\title{
Perovskit - Like Structure Functional Ceramics Syntheses on the Solar Furnace
}

\author{
Payzullahanov Muhammade-Sultanhan \\ Institute of Material sciences of SPA "Physics-Sun" Uzbekistan \\ *Corresponding Author: fayz@bk.ru
}

Copyright (C) 2014 Horizon Research Publishing All rights reserved.

\begin{abstract}
Samples a barium titanate by impact of the concentrated sunlight with a density of $200 \mathrm{~W} / \mathrm{cm}^{2}$ on the mix $\mathrm{TiO}_{2}+\mathrm{BaCO}_{3}$ are synthesized. Light influence causes synthesis of titanate of barium of tetragonal modification with the raised tetragonalyty degree in comparison with solid-phase synthesis and synthesis from fusion on the Sun simulator with a xenon lamp.
\end{abstract}

Keywords Concentrated Solar Energy, Solar Furnace, Energy Density, Material Synthesis

\section{Introduction}

Materials which properties are structural and sensitive, represent a class of functional ceramics. Treat structural and sensitive properties electric, diffusive, optical, issue, photo-electric, magnetic, etc. It is necessary to emphasize that many of structural and sensitive properties are exclusive, uncommon, arising only owing to deficiency of a crystal. For the last decades the big variety of defective structure of real crystals was revealed. Nevertheless, in the modern theory of a crystalline state the dominating role remains behind the concept of dot defects or their elementary complexes. The dot defect connected with local violation of a regularity of a crystal lattice got sense of a normal structural element of the crystal defining it properties. Defects in crystal lattices their quantity and type depend on parameters of technological process of synthesis. Researches of processes of synthesis of materials in the field of the concentrated light radiation showed that such influence increases the speed of physical and chemical processes of structuring and destruction. Possibility of instant influence of the concentrated light stream of high density (up to $700 \mathrm{~W} / \mathrm{cm} 2$ ), swimming trunks, superfast training from fusion allows to fix high-temperature phases of a certain nanometer size with various degree of deficiency.

As shows the analysis, unlike the Sun the xenon lamp gives a discrete range many short-wave ultra-violet (UV) and near infrared (IR) radiation (fig. 1). Such difference will define a priori various nature of influence of radiation of the Sun and a xenon lamp on substance. Near IK radiation makes thermal impact like heating in electrothermal furnaces.

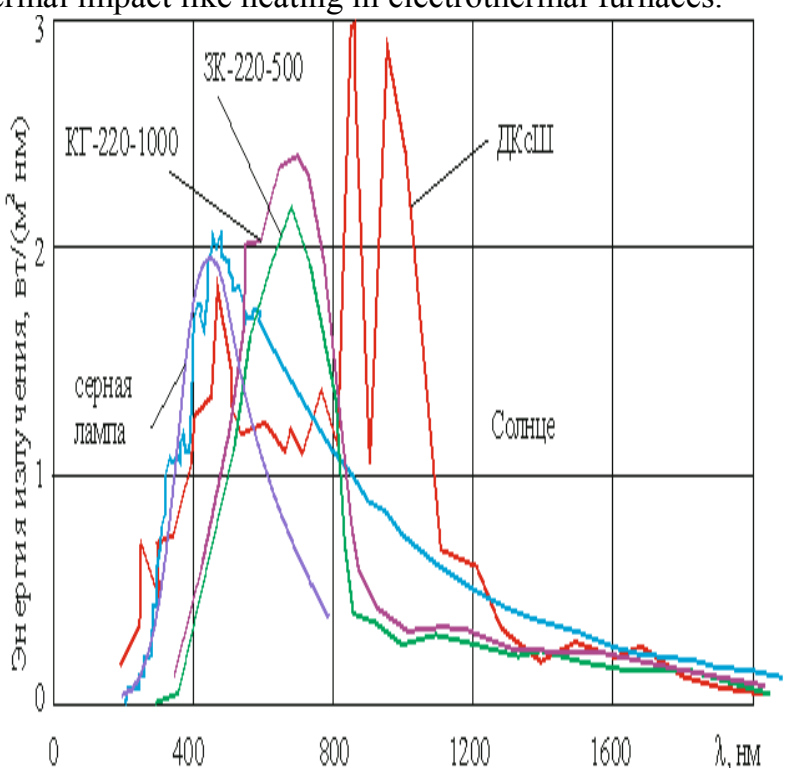

Figure 1. Ranges of radiation of the Sun and halogen simulators of the Sun

Short-wave UV radiation at doesn't get deep into a material and initiates ionization of atoms only in a thin near-surface layer, photons with get deep into a sample and are absorbed on defects. Thus, at impact on substance the concentrated light radiation of a xenon lamp physical and chemical processes will be caused thermal and ionization by the effects changing kinetics and dynamic balance of defective states, quasichemical and chemical reactions of structuring or destruction.

Concentration of sunlight by means of mirror concentrating systems is based on optical reflection of sunshine by a mirror with the back sawed aluminum layer. Therefore, the sunshine passing through glass are reflected in a surface of an aluminum layer and again pass through glass.

It is known that glass completely absorbs UV part of a solar range and passes IK radiation almost as it is good, as well as visible light (fig. 2). In a range of IK of radiation of the characteristic of glass are respectively equal: $\mathrm{T}=0,82 ; \mathrm{R}$ 
$=0,07 ; \mathrm{A}=0,11$. Owing to double passing through glass intensity of IR of radiation decreases on the average to $36 \%$. In case of use of two mirror MCS (heliostat - the concentrator) sunshine pass through glass four times and intensity of IR of a range decreases by $72 \%$.

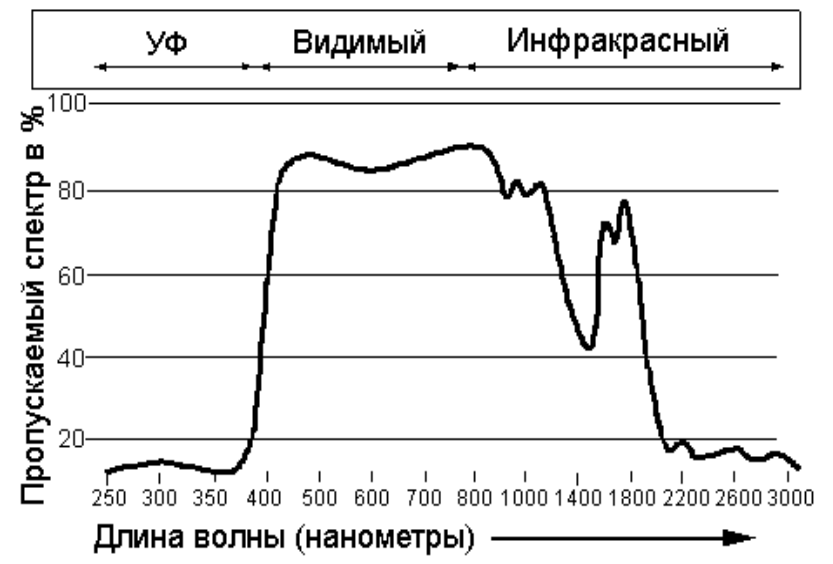

Figure 2. Dependence of coefficient of a transmission of glass on length of a wave of sunlight.

Thus, the range of the concentrated sunlight is other than that sunlight simulators on the basis of xenon lamps. At impact on substance the concentrated sunlight the kinetics and dynamics of physical and chemical processes will be caused by selective absorption.

In this work are studied radiation influence by the concentrated light stream of high density of the small solar furnace on processes of synthesis of fusion of titanate of barium of perovskite structure.

\section{Materials and Methods of Research}

Melting of materials carried out with use of the solar furnace thermal the power of $1 \mathrm{MW}$ which optical power parameters are specified in $[1,2]$.

Equation of radiation of heated bodies

$$
E=\varepsilon E_{0}=\varepsilon C_{0}(T / 100)^{4}
$$

где $\mathrm{C}=\varepsilon \cdot \mathrm{C}_{0}$ is a coefficient of radiation of a real body, $\varepsilon \cdot$ is a degree of blackness of material, $\mathrm{C}_{0}=\sigma_{0} \cdot 10^{8}=5,67 \mathrm{BT} /\left(\mathrm{M}^{2} \cdot \mathrm{K}^{4}\right)$ is a coefficient of radiation of absolutely black body, $\sigma_{0}=5,67 \cdot 10^{-8} \mathrm{~W} /\left(\mathrm{m}^{2} \mathrm{~K}^{4}\right)$ is a constant Stephan-Batsman, $\mathrm{T}-$ temperature, allows to calculate body temperature, absorbing a certain energy, according to degree of blackness of a body. In fig. 3 dependences of body temperature on energy density are given in the focal plane of the solar furnace for materials with various degrees of blackness. At calculations losses weren't considered by convection.

From fig. 3 it is visible that in E-t coal mine it is possible to notice growth of temperature of a material at the same density of the concentrated stream with growth of degree of blackness. Therefore, materials with high degree of blackness can melt at the smaller density of the concentrated stream. High degree of blackness in the mix $\mathrm{TiO}_{2}+\mathrm{BaCO}_{3} \mathrm{~B} \mathrm{a}$ temperature interval $800-1400 \mathrm{C}$ titanium dioxide $0,52-0,41$, therefore, density of energy of an order $100 \mathrm{~W} / \mathrm{sm} 2$ will be sufficient mix $\mathrm{TiO}_{2}$ for melting + possesses $\mathrm{BaCO}_{3}$

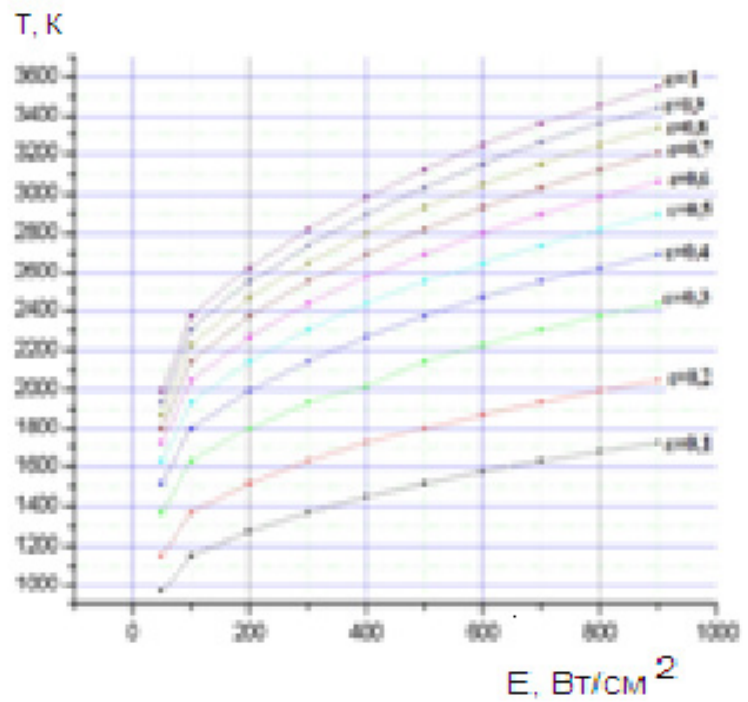

Figure 3. Dependences of body temperature on energy density on the ZKS focal plane for materials with various degrees of blackness

From the stexiometric of mixes of initial materials titanium dioxide and carbonate of barium, method of moist pressing by effort $500 \mathrm{\kappa H}$ a binding material of glue samples tablets diameter $3 \mathrm{~mm}$ the $2 \mathrm{~mm}$ thick prepared. Samples tablets were established on the focal plane of the small solar furnace and melted under the influence of the concentrated sunlight. Casting cooled in water (training) (A-type samples), and also on air (B-type samples).

The castings received after cooling of fusion, subjected to crushing in an agate mortar, tablets with a diameter of $8 \mathrm{~mm}$ method of moist pressing with a thickness of $2 \mathrm{~mm}$ prepared. The received tablets cemented at a temperature of $1350 \mathrm{C}$ endurance 2 hours, cooled with a speed $100 \mathrm{grad} / \mathrm{mines}$ (C-type samples).

For an assessment of effect of light influence as the control used the samples prepared from stexiometric mix of initial components, baked in the electric furnace at a temperature of $1300^{\circ} \mathrm{C}$ with the subsequent cooling with a speed 100 /minute (D-type samples).

\section{Results and Their Discussion}

On fig. 6 are provided diffraction patterns of A - and B-type of samples of titanate of barium. The analysis showed that in case of the tempered sample (fig. 4 and) the diffraction picture finds only background dispersion without the expressed maxima and corresponds to an amorphous condition of substance. I baked, cooled on air, manages to crystallize to what the diffraction picture in fig. 4 would testify. Such picture is well described by diffraction of $\mathrm{X}$-rays from a tetragonal lattice $(\% \mathrm{RF}=4,6) \mathrm{BaTiO}_{3}$ with parameters of a lattice of $\mathrm{a}=3.99 \mathrm{~A}, \mathrm{c}=4,04 \mathrm{~A}$. Thus the factor of a tetragonality makes $=0,012$, testifying to existence of deformation of a lattice along $\mathrm{c}$ axis. 


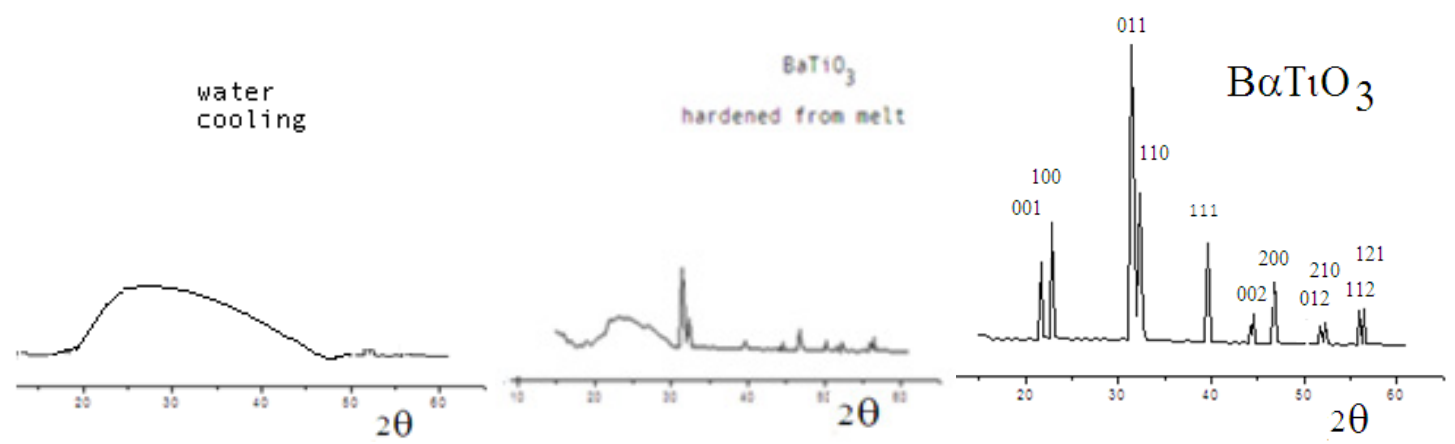

Figure 4. Roentgenograms And - B - and S-type of samples of titanate of barium.

The roentgenogram in fig. 6-c also was described by diffraction of a tetragonal lattice of barium titanate with parameters of a lattice of $a=3.99 \mathrm{~A}, \mathrm{c}=4,02 \mathrm{~A}$. Such data corresponded to degree of a tetragonality $\delta=\frac{c}{a}-1=0,010$. Reduction of degree of a tetragonality degree specifies about of deformation of a lattice after annealing of melt at a temperature of $1350^{\circ} \mathrm{C}$.

The roentgenogram of D-type of a sample was similar to the roentgenogram of C-type of a sample, with some distinction in values of parameters of a lattice of $a=3.98 \mathrm{~A}$, $\mathrm{c}=4,01$ a.raschety show that tetragonality degree in case of D-type of samples makes 0,007 , is $25 \%$ less than in case of B-type of images.

The size of crystallites is estimated on width of peak of $\mathrm{x}$-ray reflections as, where by $\mathrm{d}$ - the size of crystallite $(\mathrm{nm})$, $\lambda$ - length of a wave of $x$-ray radiation $(\lambda=0.154056 \mathrm{~nm})$, FWHM - peak width on a half-height of diffraction reflection (rad), $\theta-$ a corner of diffraction (deg)[3]

$$
d=\frac{0.9 \lambda}{F W H M \cos \vartheta}
$$

Values of semi-width of diffraction reflections allowed to calculate the size of crystallites on Sharer's formula that made $\mathrm{d} \sim 30,80$ and 160 nanometers for B -, C - and D-type of samples, respectively.

Data of the X-ray diffraction analysis testify that the size of crystallites depends on the speed of cooling of fusion. Fusion cooling on air stimulates crystallization from an amorphous state according to structural streamlining, deformation is removed. The amorphous layer between crystallites promotes elastic packing of crystallites, links them at the expense of forces of a superficial tension.

For an assessment of microstructural features counted degree of crystal degree of CK on [4] as

$$
C K=\frac{A_{\text {crystallinity }}}{\left(A_{\text {crystallinity }}+A_{\text {amorphous }}\right)} \times 100
$$

where surface $A_{\text {crystal }} \quad A_{\text {amorphous }}$ under peaks of crystal and amorphous reflections. Calculations showed that degrees of crystal degree of A -, B -, C - and D-like samples made 0 , $12,25,88 \%$, respectively.
The analysis shows that polycrystalline titanate of barium represents ceramics in which are available chaotically located from each other separate crystallites and layers of a vitreous phase (fig. 5). The quantity of a vitreous phase depends on the speed of cooling of fusion and makes from 1 to 25 вec. \%. At quite high temperatures of agglomeration the quantity of a vitreous phase will decrease to $1-2$ weight. $\%$.
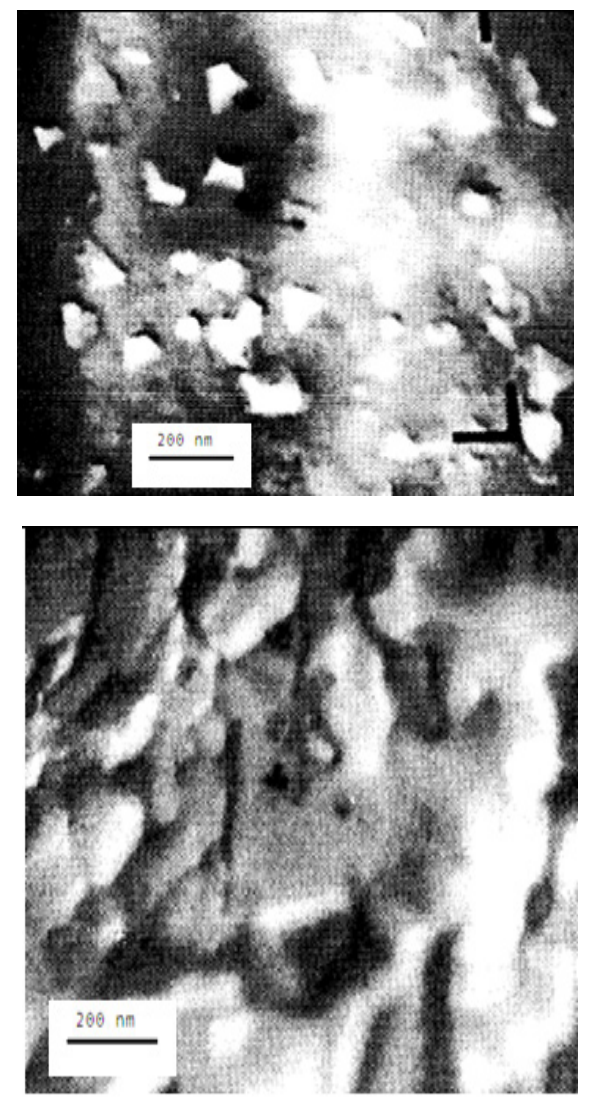

Figure 5. Microscopic pictures of samples of titanates of the barium synthesized from fusion on the solar furnace (A-type samples) and a method solid-phase reactions (D-type samples).

The observed increase in degree of crystal degree with reduction of speed of cooling of fusion testifies to homogeneity and/or coherence of intercrystalline borders amorphous layers because such character of borders promotes growth of crystallites by means of accretion of adjoining crystallites and grains. Dependence of the average size of crystallites on the speed of cooling of fusion is thus 
traced. Namely among "training - cooling in air post-annealing" the average size of grains increases in water from 40 nanometers yes 160 nanometers.

Observed effects of influence of the concentrated sunlight on mix $\left(\mathrm{TiO}_{2}, \mathrm{BaCO}_{3}\right)$ can be explained within the following assumption.

$$
\mathrm{TiO}_{2}+\mathrm{BaCO}_{3}=\mathrm{BaTiO}_{3}+\mathrm{CO}_{2}
$$

According to the phase chart $\mathrm{BaCO}_{3}-\mathrm{TiO}_{2}$ [5] on the basis of the structures used by us in the range of temperatures 1200 - $1500^{\circ} \mathrm{C}$ steadiest the phase $\mathrm{BaTiO}_{3}$ as in solid (at $\mathrm{T}<1320^{\circ} \mathrm{C}$ ), and in liquid (at $\mathrm{T}>1320^{\circ} \mathrm{C}$ ) states.

The analysis shows that values of width of the forbidden zone $\mathrm{TiO}_{2}$ and $\mathrm{BaCO}_{3}$ make $3 \mathrm{eV}$ [8] and 3,1 eV [9]. Us it is necessary that interaction of the concentrated sunlight with energy of quanta $3,1-2,6 \mathrm{eV}$ is caused by intensive absorption - with photoexcitement of an electronic subsystem of $\mathrm{TiO}_{2}$ and $\mathrm{BaCO}_{3}$ stimulating photosynthesis

The structural condition of crystallites thus is very imperfect since processes of solid-phase synthesis of a material are quite far from optimum conditions of crystallization. Crystallites contain a large number of defects as macroscopic (an unblocking, dislocations, etc.) and microscopic (vacancies and other dot defects) character. Influence of the concentrated sunlight consists in intensive defect formation at molecular level by means of a rupture of chemical bonds. The analysis shows that energy of sunlight of $180-293 \mathrm{~kJ} / \mathrm{mol}$ is commensurable with energy of ionic communications of $250 \mathrm{~kJ} / \mathrm{mol}$. At influence of sunlight process of a rupture of communications of Me-O, loss of a distant order of the leader to amorphicity and melting (destruction) proceeds. I.e. the liquid state of titanate of barium represents unstructured education - a conglomerate of small (nanodimensional) crystallites and intercrystalline layers of homogeneous structure (twinning borders). Chemical processes in a liquid phase proceed with a high speed, owing to increase in coefficients of diffusion of reagents at orders in comparison with solid-phase synthesis. The liquid state is characterized by also high homogeneity. Depending on the speed of cooling it is possible to receive microstructures with various degree of orderliness. Process of crystallization is defined generally by diffusive transfers, improvement of crystallites due to streamlining of atoms and the directed movements of dot and extended defects to a grain surface, promoting accretion of crystallites in the field of contacts. The intercrystal layers, connecting crystallites, in our case, glass phase, the glue role at the expense of forces of a superficial tension carries out. In borders of accretion of different crystallites structural coordination like twinning borders can take place. If such coordination is the leader, in a macrosample of ceramics texturing has to be observed. Volume ratios of crystallites and a layer (crystal degree), and also their physical properties define final macroscopic set of electrical properties of segnetoelectrical ceramics,

It should be noted that unlike electrothermal heating influence by a solar stream has the directed character leading to directed deformation of a lattice, causing microtension giving to structure friability, promoting acceleration of processes of diffusion of structuring at crystallization in the presence of coherent the inter grain of borders.

\section{Conclusion}

Thus, it is possible to conclude that

- at synthesis of titanate of barium from fusion degree of a tetragonalnost of a perovskite $\delta=$ with / and -1 increases by $75 \%$ in comparison with synthesis of solid-phase reactions;

- the broadening of x-ray diffraction reflections in case of synthesis from fusion testifies to high degree of deficiency and the small sizes of crystallites;

- at synthesis of titanate of barium from fusion friability of structure grows in comparison with solid-phase synthesis.

\section{REFERENCES}

[1] Solntse scientific-industrial complex. Bizerkalny polyheliostately solar furnace with a thermal power of 1000 kW. Solar technology. 1987, No. 6, page 3

[2] Abdurakhmanov A. Akbarov R. Yu. Gulamov K. G. The mirror concentrator systems for solar power and technology installations and their efficiency when using solar radiation selective receiver//J.Phys. IV 1999 France 9.

[3] Mirkin L.I. X-ray diffraction analysis. Moscow, World 1961, $237 \mathrm{p}$

[4] Ulrike Diebold, Min Li, Olga Dulub, Eleonorel. D. Hebenstreit and Wilhelm Hebenstreit. The Relationship Between Bulk And Surface properties Of Rutile TiO2 (110) Surface Review and Letters, Vol. 7, Nos. 5 \& 6 (2000) 613-617

[5] Ziegel R., Howell Dzh. Heat exchange by radiation. М.:Мир, 1975, 935c.

[6] Negas F. Roth R. S. Parker H.S. Minor D. J. Solid State Chem., 1974, vol.9, N3, p. $297-307$

[7] McCarthy G.J. Whie W.B. Roy R. j. Amer.Ceram. Soc. 1969, vol. 52, No. 9, P-463-467

[8] S. V. Halameyda. Features of synthesis of nanodisperse titanate of barium and research of its properties. HFTP 2010. T. 1 . . No. 4. Page 441-449 